\title{
The need for science in the range livestock industry: How ranchers evaluate and use science in land management
}

\author{
Cassie Cady
}

I thank Clayton Marlow for inviting me to be a part of this SRM symposium. I am a rancher and student of ranching and have worked on the Checkerboard Cattle Company (CCC), where I'm co-manager, since 1976. The ranch is located on the North Fork of the Musselshell River, in the Castle and Little Belt Mountains, Montana. Headquarters are over 5200 feet in elevation and the terrain rises from there. We are surrounded on several sides by US Forest Service (FS) lands. The ranch has evolved with the use of these federal lands even in the late 1800's (before the FS existed) and continues to hold FS leases on 5 allotments with about $60 \%$ of our cattle grazing on FS allotments during summer months.

I tend to view science as an aid in our efforts to ranch sustainably. Ideally, to be most useful to me, science should be easily understood, unbiased, and repeatable. However, separating well designed, rigorously tested science from that which is opinion or observation can be difficult. We see information that has the appearance of science but seems to have been selected to bolster specific, preset agendas rather than presenting objective results that can be reproduced. Unlike information derived from conjecture, results from scientifically conducted studies can readily be seen. Performance of our AI calves, for example, is physical evidence that the science used to produce the technology is valid. It will take four years from the moment of successful AI conception until we can get carcass data on the first calf born to that heifer. Four years seems a long time to wait. But we'll take the time so that we can determine the quality of product we are raising. We'll use the data to make culling and bull selection decisions and to market our calves. Unlike livestock genetics, the validity of scientific premises in range and forestry is slow to reveal itself and more difficult to assess. In an effort to improve the grass resource we are raising on the ranch, we'll also take the time. We use range inventory data to help us in making range management decisions. We set goals, weigh what we learn from outside sources against our own experiences, and choose a course of action. We try one thing and if it doesn't work we try another. We monitor results to determine if and how our actions work toward our purposes and needs; and then we adjust as needed to respond to changing conditions. To evaluate the results of our range management on the ranch, we use grazing records, monitoring photo-points, and permanent transects. In addition, we have established permanent monitoring transects on some of our FS allotments. We have also relied on the historic range monitoring done in our allotments by Lewis and Clark National Forest personnel. However, in recent years, this Forest has begun to use an ecosystems approach, called Ecodata, to make management decisions. We are concerned that they are using this process as though there have not been livestock grazing on the allotments for decades.
I'd like to describe the implementation of the Ecodata methodology used by the Lewis and Clark National Forest and have you judge the validity of the science used in this example. That's your job. First I'll review the Ecodata process as it was implemented on our grazing allotments and identify several concerns that arose as Ecodata was implemented, citing examples that we documented. These examples raised questions about the quality of science used by the Forest Service. Finally, I'll draw some conclusions about our first hand experience and make some recommendations to this audience.

\section{Timeline}

In 1987, Region I of the USFS made a decision to use the Ecodata system it had developed for analysis and classification of natural resources. Ecodata is described as "A sampling method designed for multi-resource inventory and monitoring application that can be used in conjunction with other data collection procedures, such as range inventory. Ecodata sampling methods provide for description of vegetation types." (Final EIS, Chapter 8, p. 4) It was implemented in an attempt to establish a standardized method for vegetation inventory and monitoring and, secondarily, to "promote the integrated use of vegetative data by all types of resource managers" (Winslow, 1995). I don't understand all the complexities of the Ecodata system, but in this method plant communities are classified based on species composition by percent plant canopy cover; ecological status is described as floristic similarity of current vegetation to potential vegetation (climax).

Because the Lewis and Clark National Forest (LCNF) of Region I consists of widely-dispersed districts, this Forest elected first to combine allotments located closely to each other into "allotment groups" to facilitate Ecodata assessment. This would allow Forest Interdisciplinary Team (IDT) specialists to concentrate resources in assessing several allotments at once, rather than focusing on one allotment at a time.

In May of 1992 Forest Service (FS) personnel met with the 19 Castle Mountain permittees to let them know that the first allotment group to be studied by the new method would be the Castles. To facilitate information gathering and dispersion, and to deal with the FS as a group, permittees reinstated a defunct organization called the Castle Mountain Livestock Association (CMLA). As secretary/treasurer of the CMLA, I've been involved in the dealings between the CMLA and FS from the beginning. The CMLA position has been proactive in the process of trying to help the FS accomplish what it wants. We asked the FS for its goals and for the chance to be a part of the IDT. Initially, the FS had no goals to share and told us that the IDT would develop goals as it went along. In January of 1993, the CMLA was finally allowed to sit in on the IDT meetings as observers, not participants. The IDT meetings 
were long but it was fascinating to observe from the inside the federal government at work. I came away with a much greater appreciation for the difficulties government employees wrestle with in dealing with policies and special interest groups. Permittees wrestled too-with learning about the NEPA process, Ecodata, seral states and with judgment about the value of the land management proposals presented within the IDT team. We asked that if we could not actually participate, could an independent, third-party range scientist sit in on the IDT as advisor and participant. We were told that a ranger or range con would be happy to meet with any experts to discuss their questions. We asked for the data generated by the Ecodata survey and were given the entire record. We also asked to be able to submit an alternative for evaluation and were given permission to do so. In September, 1993, we submitted an alternative in which costs of proposed structural improvements were $\$ 1600$ less than those proposed in the FS Preferred Alternative (Alt 10); in addition, we requested no reduction in AUMs. In a comparison of the ten alternatives evaluated in the Final EIS, the CMLA alternative (Alt 5) came in 9th - just above the No Action Alternative (Alt 1) in analysis of the categories of Upland Status (\% use), Vegetation < DPC (desired plant community), Fisheries Trend (decline), Sensitive Fish (decline), and Wildlife Riparian (decline). The No Grazing alternative (Alt 2) showed the greatest resource improvement (more rapidly) over any of the other alternatives in all categories. Alt 10 (Preferred) called for a reduction in AUMs and was believed by the FS decision-maker to be a good compromise of cost of improvements, protection of resources, and livestock grazing. The CMLA questioned the justification of spending over $\$ 164,000$ on structural improvements and taking reductions in AUMs.

The CMLA began to ask for help from outside range experts early in our participation. In September of 1992, we hired Rangehands, Inc to do a cursory review of the Castles to point out the problems they saw. They described problems in livestock distribution (not numbers), and, in a few allotments, season-long grazing. At a range monitoring field-day in June of 1993, John Lacey and Robin Tierney, PhDs in range science from MSU, reread an old Parker three-step site and found the transect approaching maximum in forage density index and composition. The FS Ecodata classification of the polygon* $(450+$ acres total) in which this transect is located showed the polygon to be in low seral or "poor" condition. We also questioned outside experts about a livestock distribution formula developed by the FS- using $8 \%$ slope and .15 mile distance from water - to determine carrying capacity. In July of 1995, we again hired Rangehands, Inc.; this time to verify available forage production on some "key" polygons by harvesting and weighing samples. The analyses suggested that FS estimates of available forage were often too low, and sometimes extremely low. Consequently the CMLA requested a Section 8 process in 1994 and attempted to initiate a CRM process in 1996. Neither of these processes were successful. The FS released its Castle Mountain DEIS in August of 1995; the Record of Decision (ROD) / Final EIS-Castle Mountain Range Analysis (FEIS) was released in February of 1997.
The Final EIS, (Chapter 3, p.2) describes the methodology of classification of plant communities by site type (productivity), community type (seral stage), etc. "Plant communities were assigned to the map polygons based on the similarity of the polygon field description to the classified plant community description." (Italics added) A map showing polygons looks like a jigsaw puzzle, with each puzzle piece representing a community classification (grassland, riparian, conifer, broadleaf, etc.). Each polygon is numbered and the number is logged into Ecodata with specific information relative to habitat characteristics, size and so forth. Polygons may vary in size from one acre to over 500 acres.

\section{Definitions}

The following definitions used by the FS may differ somewhat from what is generally understood and accepted. They are taken directly from the Final EIS.

\section{-potential natural community (PNC)-}

The biotic community or composition of plant species that would naturally occur under minimally disturbed conditions (i.e. little occurrence of grazing, fire, mechanical disturbance or non-native plant invasion). (Chapter 8, p.9) -key areas-

The areas or portions of the range that are preferred by livestock and are grazed to the allowable use first. For cattle, these areas are generally riparian areas of gentle gradent and near water. The Key area guides the management of the entire area of which it is a part. (Chapter 8, p.6)

-Allowable Use-

The amount of forage planned to be used to accelerate range improvements. (Chapter 8, p.1)

Is this audience familiar with these definitions? Are scientific data available to support these definitions?

In the first place, natural resources are dynamic and have historically received disturbance - in the form of fire, grazing, and mechanical impacts by millions of hooves, wind and water. Also, my concern as a rancher is that application of an allowable use standard may not move plant communities in key areas to a higher seral state as required by the FS. In his essay entitled The Illusion of Ecosystem Management, Allan K. Fitzsimmons describes ecosystems as being a fabrication of the human mind. He states "While the ecosystem concept may be helpful as a tool for researchers to better grasp the world around us, it is far too ambiguous to serve as an organizing principle for the application of federal law and policy. As spatial units, ecosystems represent a geographic free-for-all." Range experts in this audience should be among those to debate the accuracy of these terms and the suitability of "ecosystems management". As you do, please consider the following.

\section{Agency Approach}

Historically, data collected in the Castles included readings of 30 Parker three-step transects in the 1950s, '60s and '70s. In addition to the Parker data, records of numbers of livestock, on/off dates (total AUMs) and dates of moves through pastures within the allotments are kept annually. Paced transects describing range condition have been done in several areas over the years and those results are available, but few actual utilization measurements are available. All Parker transects 
are located on upland sites. The majority of transects were rated in good condition, some in fair condition, a few in excellent, and none in poor. However, the fifty years of Parker three-step data have been dismissed by the LCNF as being unable to be integrated or correlated into Ecodata, and so are no longer used. None of the other historical data were used in the development of the following methodology.

Under the Ecodata process, estimates of allotment stocking rates are calculated based on four factors:

1. existing condition relative to desired condition,

2. actual use relative to allowable use,

3. maximum carrying capacity estimates, and

4. effective carrying capacity estimates.

1. Existing condition relative to desired condition.

The FS began in 1991 by mapping the allotments into polygons. The assessment of each polygon is based on a one-snapshot-in-time estimate. For each polygon FS personnel do an ocular observation to determine:

a. dominant species (determined by percent plant canopy cover)

b. site type (ST) based on productivity on uplands or susceptibly to damage in riparians (where ST1=most productive, ST3=least productive)

c. community type (CT) or \% of floristic similarity to PNC (where CT1=PNC, CT2=high seral state, CT3=mid, and CT4= low)

d. average slope of polygon.

The "desired future condition (DFC)" is plant communities in high or higher (PNC) ecological status with some exceptions. Exceptions include those polygons in low seral state which are not expected to improve because they contain large amounts (greater than 20\%) of introduced species such as timothy, Kentucky bluegrass, and brome. Therefore, the emphasis is to move polygons that are determined to be in mid-seral state to high seral. The manner in which seral states will be improved is by applying allowable use standards.

2. Actual use relative to allowable use.

Historic use data and trend were not considered in the process of developing the new standards. Allowable use standards were developed based on published grazing studies and FS Handbook guidelines. Following are standards of allowable use for different plant community types and different grazing systems as listed in the Final EIS.

Desired

\begin{tabular}{|c|c|c|c|c|}
\hline Plant Community & SL \% Use & DR\% Use & RR1\% Use* & RR2\% Use* \\
\hline PNC & 20 & 30 & 40 & 50 \\
\hline High Similarity & 35 & 45 & 55 & 65 \\
\hline Mid Similarity & 40 & 50 & 60 & 70 \\
\hline Low Similarity & 45 & 55 & 65 & 75 \\
\hline
\end{tabular}

* $\mathrm{SL}=$ season long; $\mathrm{DR}=$ deferred rotation; RR1= rest rotation $1 ; \mathrm{RR} 2=$ rest rotation 2.

The average use over the rotation cycle assumes a four-pasture, one year system for

RR1 systems and a five-pasture, two year system for RR2 systems.

(Final EIS, Chapter I, p.11)

In his Plant Requirements for Prudent Grazing, Martyn Caldwell concluded that "proper use factors ... imply a level of precision and understanding of range plants and community dynamics that, for the most part, do not exist." He went on to say that "...the traditional condition and trend analysis is probably the only suitable management alternative until a quantita- tive understanding of range plant function permits a more refined basis for management." Are scientific data available to verify that the above standards will move plant communities to a higher seral state? Will, in fact, $45 \%$ utilization move a FESIDA/AGRSPI community that is in mid-seral state $(15 \%$ FESIDA, 5\% AGRSPI) to high (20\% both species)?

\section{Maximum carrying capacity estimates.}

The FS determined forage production by clipping plot samples using a Daubenmire quadrat of $1.4 \mathrm{sq} \mathrm{ft}$. Most sampling was done by seasonal trainees. No permanent plots were established so sample sites cannot be accurately revisited. Nearly every sample was taken from a different polygon in several different allotments. Although data was collected at the end of a droughty period, weather records were reviewed by the FS to determine that precipitation was within a range of average conditions From the clipping data forage production tables were developed for each of 94 plant community types. Results of clipping and weighing of 905 samples of forage taken from 1991 through 1995 (and augmented with published data from Mueggler and Stewart, 1980) were compiled into a publication (unique to the LCNF) to be used in mapping polygons. Very few historic clipping studies were available and so historic forage production records were not used in development of these tables. FS personnel can look at a polygon (in any of the mountain ranges within the LCNF), place it into a specific classification, and look it up in Range Vegetation Classification 1996 to find ecological status and forage production in pounds per acre for each site type/community type given in the respective tables.

Maximum carrying capacity may be determined by one of two ways, neither of which use long term historic grazing records. Note that, in each of these methods, grazed AUMs are calculated, not measured.

a. production basis:

1. total usable forage $(\mathrm{lbs} / \mathrm{ac})=$ forage production (lbs/acre) $* \%$ allowable use

2. total pounds available $=$ total usable forage $*$ acres

3. maximum AUMs = total pounds available

$780 \mathrm{lbs}$ (forage required by a cow for a month)

b. utilization basis:

1. maximum AUMs $=\underline{\% \text { weighted average allowable use }}{ }^{*}$

\%actual use

\# AUMs actually grazed in that year

4. Effective carrying capacity estimates.

"Effective carrying capacity" becomes the number of AUMs estimated to be able to be grazed by the time allowable use is reached on key (heavily used) areas and may be estimated by one of two methods.

a. PAUT formula:

This distribution formula using the average slope of a polygon (determined in the field) and average distance from water (determined from maps) is applied to adjust from maximum capacity in an attempt to take into consideration uneven use within a pasture due to slope and distance from water. No consideration was given by the FS for historic grazing capacity based on allotment use records. The following formula was developed using data from 140 polygons in 14 pastures in 4 allotments and is unique to the LCNF: 
1. predicted pasture utilization

$$
\begin{aligned}
\mathrm{PAUT}= & (\{-3.8 \sqrt{\mathrm{PASL} * \mathrm{PAWA}}+13.2 \\
& \sqrt{\mathrm{POSL} * \mathrm{POWA}}=\mathrm{POUT}\} / 9.2)^{2}
\end{aligned}
$$

Where:

PAUT = predicted pasture utilization (in percent)

PASL = pasture weighted average slope (in percent)

PAWA = pasture weighted average distance to water (in miles)

POSL = key area polygon slope (in percent)

POWA = key area polygon distance from water (in miles)

POUT = key area polygon allowable use (in percent)

2. maximum carrying capacity $=\underline{(\# a c r e s * l b s / a c r e * \% \text { allowable use })}$

\section{$780 \mathrm{lbs}$}

3. effective capacity (AUMs) = max. carrying capacity*PAUT weighted pasture allowable use [ave. allowable use of all polygons in a past. (weighted for forage production)]

4. head months $=\underline{\text { AUMs }}$

1.32

[the AU factor for cow/calf (c/c); or, .76 for yearlings]

b. actual use by polygon

This is a method also used by the FS to adjust maximum capacity. Because few historic actual-use measurements are available, and those available are located primarily in key areas (very few available for more lightly used areas), a onetime utilization rating of "suitable" polygons is applied.

1. effective capacity (AUMs) $=$ max carrying capacity(as figured above) $* \%$ actual use (where actual use is $\Downarrow$ allowable use) $\quad 780 \mathrm{lb}$

2. effective capacity (AUMs) = max carrying capacity $* \%$ allowable use

(where actual use is $\Uparrow$ allowable use) $\quad 780 \mathrm{lb}$

3. head months $=\frac{\text { AUMs }}{1.32(\mathrm{c} / \mathrm{c})}$

Through application of this methodology AUMs in the Castles have been reduced $17 \%$. These reductions occur in spite of building improvements (fencing and water developments) originally estimated to cost over $\$ 164,600$ (Table 1). The FS policy states that two years of consecutive applications of both old and new methodology would allow for a good transition into management based on the Ecodata process. However, this policy has not been followed. Therefore, it is difficult to tell if AUM reductions are a result of climate in the year of assessment, change in methodology, or what. In comparing Ecodata to the SCS Range Condition Analysis (RCA) sampling method, Susan Winslow found that a change from the old RCA method of range classification to Ecodata may result in a reduction of range condition score by 15-20\%. She states: "Range inventories conducted with Ecodata methods may indicate that vegetation resources have declined when the change in methods alone could account for the lower score and results may not be related to management changes." (Winslow, 1995)

Winslow's observations appear to describe what has happened in the South Little Belt Allotment group.The South Little Belt allotment group (including CCC allotments) were assessed using Ecodata in the summer of 1997 during a very

$\underline{\text { Table } 1}$

Allotment Group/

(post NEPA)

Castle Mtn

Sun Canyon

Belt Creek

N. Little Belts

Judith (17) of the formulas described above. For example, the formulas predicted that total $\mathrm{NF}$ reductions in the Castle Mountain group will be 17\% in order to stay within allowable use guidelines, and their initial reduction in NF authorized use is $10 \%$. The rest of the reduction may occur later based on monitoring standards. Initial reductions in authorized use (\% AUMs) appear in parentheses and include administrative changes.

**This reflects large AUM reductions permittees already took in the 1930s.

***Without vegetation treatment (prescribed burn) costs.

The LCNF is divided into 12 allotment groups, including one sheep group. The five groups listed above show allotment numbers after NEPA. The remaining 7 allotment groups contain 144 total allotments, pre-NEPA, including Special Use and Administrative. Data has been collected on 4 of those left and NEPA work has begun. Three allotment groups remain to be assessed.

favorable growing season. We at $\mathrm{CCC}$ wondered what the effects of a drier year would have on forage production figures and so did our own forage production sampling. We clipped, dried, and weighed ten plots in each of six polygons in August and September of 1999. Our sampling quadrat was a hoop totaling $4.8 \mathrm{sq} \mathrm{ft}$ of area. Although precipitation for 1999 was lower than normal, we found actual production in those polygons to be higher than stated in the LCNF Range Vegetation Classification handbook. In both CMLA sampling done with Dr. Sindelar in 1995 in the Castles (1. below), and CCC sampling done in 1999 in the Little Belts (2. below) we have found FS production figures to be lower. We believe that the FS use of the small Daubenmire quadrats on a small number of sites to sample biomass is inappropriate from a scientific standpoint as well.

\begin{tabular}{|c|c|c|c|}
\hline Polygon \# & USFS & $\underline{\text { CMLA }}$ & Difference \\
\hline & Estimate (1992) & Estimate & \\
\hline 813 & 1300 & 2050 & $+58 \%$ \\
\hline 252 & 1300 & 2130 & $+64 \%$ \\
\hline 907 & 1300 & 1490 & $+15 \%$ \\
\hline 781 & 900 & 2240 & $+149 \%$ \\
\hline 57 & 900 & 1740 & $+93 \%$ \\
\hline 879 & 800 & 1500 & $+88 \%$ \\
\hline 181 & 2000 & 1160 (post-grazing) & NA \\
\hline 357 (inside) & 1600 & 1390 & $-13 \%$ \\
\hline 357 (outside) & 1600 & 1030 (post-grazing) & NA \\
\hline 84 & 2100 & 2360 & $+12 \%$ \\
\hline
\end{tabular}

1. CMLA Forage Review - July, 1995

Notes: CMLA figures shown are for grass only, in pounds/acre. The FS figures are for total standing forage.

CMLA harvest sampling occurred July 10-11 during a growing season which was characterized by normal precipitation and below-normal temperatures. Cool temperatures delayed vegetation development by approximately 2 weeks. Standing forage crop was not fully developed at the sampling. 


\begin{tabular}{|c|c|c|c|}
\hline Polygon \# & $\frac{\text { USFS }}{\text { Estimate (1992) }}$ & $\underline{\text { CCC Estimate }}$ & Difference \\
\hline 627 & 700 & 2690 & $+284 \%$ \\
\hline 634 & 1100 & 3770 & $+243 \%$ \\
\hline 592 & 1200 & 2180 & $+82 \%$ \\
\hline 312 & 1200 & 5030 & $+319 \%$ \\
\hline 371 & 1200 & 3470 & $+189 \%$ \\
\hline 1116 & 700 & 1540 & $+120 \%$ \\
\hline
\end{tabular}

Notes: CCC figures shown are for total standing biomass, in pounds/acre.

The 1999 season was characterized by a cold, late spring and hot, drier than normal growing season.

We have also found what appear to be mistakes in polygon classification for several polygons. For example polygons containing over $50 \%$ timothy were classified as being in midseral state. We feel that the application of an allowable use standard will not move the predominance of timothy out of these polygons. Instead, we fear that FS personnel rating these polygons in the future may very well conclude that the allowable use standard did not protect these polygons judged to be in mid-seral state in the original 1997 appraisal. The polygons will be found to be in low when they are reassessed, and the "decline" in seral state will necessitate further reductions in AUMs.

The FS underestimation of forage production translates into automatic, immediate cuts in carrying capacity and permit numbers. Forest Service errors in classification of polygons and reliance on utilization standards may result in future cuts as well. All cuts adversely affect those ranches whose economic stability is tied directly to the historic and customary use of the allotments.

Let's look at the subject of riparians briefly. It is true that years ago riparian areas were considered sacrifice areas. This biased position needed to be changed. Now the position is biased just as badly in the opposite direction. We see large areas of streams completely fenced out and AUMs in whole allotments eliminated or reduced to the carrying capacity of the riparian areas contained therein. When the FS told us at the beginning of this process that they were going to look at the big picture, I was tickled. I thought finally, and I had an image in my mind of all the players standing on the top of a hill looking out on all the resource and deciding what we wanted it to look like. As the process evolved, I realized that the position of the hill had changed. It had gotten flipped upside down and had landed with the tip resting (and the health of the entire resource balanced) in the $1-2 \%$ of the resource called riparian. I understand the importance of riparian areas. I also understand that the health of riparian areas is entwined with and dependent upon the health of the uplands, but let's ground our positions in reason and common sense. These resources evolved with use. Use does not automatically constitute abuse of our natural resources. I am confident that livestock utilization of rangeland can be beneficial. We can use our federal land resources and keep them healthy. I believe valid science and experience have verified this, and can provide means for us to overcome existing problems.

\section{Conclusion}

Fairly and accurately applied by skilled, knowledgeable personnel, Ecodata may become a useful tool. But it cannot be validated without historical trend data. Our participation in and close-up review of the LCNF Ecodata procedure as it was applied in the Castles and Little Belts leads us to conclude that it has serious flaws. It not only seriously underestimated the carrying capacity of our allotments, but evidenced poor quality control in field application as indicated by the lack of ability to relocate sample sites, and by having sample sites too small in size, too few in number, and taken in different polygons. We question the scientific validity of the outcomes and the management approach of a process that fails to set measurable goals early on or closely involve the permittees who have utilized the allotments for many decades.

We worry that using low forage production figures, throwing out historical data, and using utilization standards as goals rather than as management tools will set resource managers up for failure. Ranching is a rigorous business encompassing many crucial decisions and requiring application of a variety of disciplines. We look for practical, technological uses of the scientific knowledge that has been compiled to improve production, not hinder it.

\section{Recommendations}

SRM can help by:

a. developing and using a consistent and understandable working vocabulary,

b. continuing to educate land managers and others about the role of ungulate use in range resource management,

c. helping to differentiate between valid, impartial science and opinion, and

d. promoting the hiring of range people to do range work.

\section{$\underline{\text { References }}$}

Caldwell, Martyn M. "Plant Requirements for Prudent Grazing,", Developing Strategies for Rangeland Management,1984, National Research Council/National Academy of Sciences, pp. 117-148.

Fitszimmons, Allan K. "The Illusion of Ecosystem Management," PERC Reports, December, 1999 pp.3-5.

USDA U.S. Forest Service. Range Vegetation Classification 1996. Lewis and Clark National Forest.

USDA U.S. Forest Service. Final EIS Castle Mountains Range Analysis, Lewis and Clark National Forest, February 1997.

Winslow, Susan R. A Comparison of Range Condition Analysis and Ecodata to Evaluate Seral Stages. June, 1995. MSU, Bozeman, Montana.

The author is from Martinsdale, Montana 